\title{
Laboreal
}

Volume $9 \mathrm{~N}^{\circ} 1$ | 2013

Varia

\section{Acompanhar as evoluções do trabalho e da saúde : EVREST, um dispositivo comum para usos diferenciados}

Seguimiento de la evolución del trabajo y de la salud: EVREST, un dispositivo común para usos diversificados

Suivre les évolutions du travail et de la santé : EVREST, un dispositif commun pour des usages diversifiés

Monitoring changes in work and health: EVREST, a common tool for diverse uses

Anne-Françoise Molinié e Ariane Leroyer

\section{(2) OpenEdition}

\section{Journals}

\section{Edição electrónica}

URL: http://journals.openedition.org/laboreal/6213

DOI: $10.4000 /$ laboreal.6213

ISSN: 1646-5237

Editora

Universidade do Porto

Refêrencia eletrónica

Anne-Françoise Molinié e Ariane Leroyer, «Acompanhar as evoluções do trabalho e da saúde EVREST, um dispositivo comum para usos diferenciados », Laboreal [Online], Volume $9 \mathrm{~N}^{0} 1$ | 2013 posto online no dia 01 julho 2013, consultado o 04 outubro 2019. URL : http:// journals.openedition.org/laboreal/6213; DOI : 10.4000/laboreal.6213

Este documento foi criado de forma automática no dia 4 outubro 2019

Laboreal está licenciado com uma Licença Creative Commons - Atribuição-NãoComercial 4.0 Internacional. 


\title{
Acompanhar as evoluções do trabalho e da saúde : EVREST, um dispositivo comum para usos diferenciados
}

\author{
Seguimiento de la evolución del trabajo y de la salud: EVREST, un dispositivo \\ común para usos diversificados \\ Suivre les évolutions du travail et de la santé : EVREST, un dispositif commun \\ pour des usages diversifiés \\ Monitoring changes in work and health: EVREST, a common tool for diverse uses
} Anne-Françoise Molinié e Ariane Leroyer

\section{REFERÊNCIA}

Artigo original : Molinié, A.F., \& Leroyer, A. (2011). Suivre les évolutions du travail et de la santé : EVREST, un dispositif commun pour des usages diversifiés. Perspectives interdisciplinaires sur le travail et la santé [En ligne], 13-2, mis en ligne le 01 novembre 2011, consulté le 26 juin 2013. URL : http://pistes.revues.org/1852.

1 O dispositivo EVREST (ÉVolutions et RELations en Santé au Travail1) é um observatório plurianual por questionário, construído em colaboração por médicos do trabalho e investigadores, de forma a poder analisar e acompanhar diferentes aspetos do trabalho e da saúde dos trabalhadores assalariados.

2 A recolha dos dados apoia-se num questionário bastante curto, numa página frente $\mathrm{e}$ verso, preenchido durante as consultas (ver questionário em anexo). o questionário foi pensado para ser próximo da entrevista habitual sobre saúde no trabalho, facilitando, assim, a sua integração nas consultas de medicina no trabalho. As questões relacionamse com as condições de trabalho, a formação, o estilo de vida e o estado de saúde no 
momento da entrevista. A forma de abordar o trabalho é simultaneamente abrangente, pela diversidade de domínios evocados (mudança de trabalho e sua eventual ligação com a saúde, horários de trabalho e regularidade dos mesmos, constrangimentos de tempo e pressão temporal, significado e experiência de trabalho, carga física, exposição a certos riscos, formação dada ou recebida), e sucinta, tendo em conta o reduzido número de questões em cada um destes campos. A formulação das questões sobre o trabalho recorre à terminologia habitualmente utilizada em inquéritos nacionais de referência.

3 Este dispositivo visa, por um lado, constituir uma base nacional para trabalhos científicos, partindo de uma amostra de trabalhadores assalariados vistos durante as consultas de medicina do trabalho por médicos que aceitaram participar no EVREST voluntariamente e, por outro lado, permitir a cada médico participante (ou a um grupo de médicos que tenha decidido trabalhar em coordenação) produzir e analisar os seus próprios dados, de forma a enriquecer as reflexões sobre o trabalho e a saúde numa coletividade de trabalho. Trata-se, pois, de um dispositivo comum a atores relevantes provenientes de mundos profissionais diferentes e que se inscreve num espaço de partilha entre eles, mas também que permite que cada um deles se aproprie (ou o adapte) ao interior da sua própria atividade e dos seus objetivos.

O interesse do dispositivo EVREST, o seu contributo para o conhecimento e o debate sobre as evoluções do trabalho e da saúde dos trabalhadores assalariados, mas igualmente as dificuldades com que é confrontado, devem ser analisados em função do que está em jogo ao nível das suas particularidades como uma operação de coconstrução e de acompanhamento de informações sobre o trabalho e a saúde dos trabalhadores, mas também como um dispositivo que articula a produção de dados nacionais e um uso ao "nível do terreno" pelos médicos do trabalho. A tensão entre a estrutura partilhada que permite o trabalho comum e os usos "locais" é uma dimensão de base do EVREST. Estas características parecem-nos bastantes próximas das mencionadas por Susan Leigh e James R. Griesemer (Star \& Griesemer, 1989) ao proporem a noção de "objeto-fronteira" para analisar os mecanismos de coordenação do trabalho científico numa situação de cooperação entre atores provenientes de diferentes "comunidades de prática".

Iremos começar então por apresentar rapidamente esta noção e a sua pertinência para compreender o dispositivo EVREST. Numa segunda parte voltaremos às convicções partilhadas pelos atores provenientes de mundos profissionais diferentes, partilha sem a qual a cooperação em torno do projeto EVREST não seria possível. Esta ideia conduzirnos-á a uma terceira parte, onde serão apresentados os "objetos" que estruturam o espaço de partilha. Finalmente, iremos concluir com a análise dos desafios e tensões que constituem a trama sobre a qual deverá ser tecida a perenidade do dispositivo.

6 A nossa participação no dispositivo permite-nos conhecer de forma aprofundada a longa história da sua construção e das múltiplas negociações que surgiram ao longo deste processo. No entanto, ela dificulta o distanciamento necessário para uma análise da diversidade das práticas associadas à emergência desta "infraestrutura". Estamos ambas profundamente implicadas no dispositivo nacional EVREST, no seio da equipa de projeto nacional. Uma de nós tem uma longa experiência de quantificação no âmbito do trabalho e da saúde e de reflexão sobre a posição desta abordagem em ligação com as preocupações da ergonomia da atividade (Molinié \& Volkoff, 1982, Molinié, 2003, Volkoff \& Molinié, 2010). Em colaboração com Serge Volkoff, participou na emergência 
do dispositivo no seio de uma grande empresa aeronáutica francesa e desempenhou, em seguida, um papel de passador entre esta experiência e as reflexões de um grupo de médicos de serviços interempresas, reunidos no seio de um grupo "Epidemiologia". A outra, mais ancorada inicialmente na investigação em epidemiologia e saúde pública, descobriu o EVREST no momento da colocação em prática da fase de experimentação do dispositivo nacional numa região francesa. Esteve fortemente implicada na extensão deste dispositivo, nas ferramentas das quais ele é dotado, nos debates aos quais ele deu lugar, nos resultados que ele permitiu produzir a diferentes níveis, etc. Assegura atualmente a direção do grupo de interesse científico que se foi construindo em torno do EVREST.

\section{Um dispositivo decorrente do intercâmbio entre investigadores e médicos do trabalho}

\subsection{A noção de "objeto-fronteira"}

7 Susan Leigh Star e James R. Griesemer (supra citados) forjaram a noção de "objetofronteira" para descrever e caracterizar os diversos processos pelos quais os atores provenientes de mundos sociais diferentes, mas chamados a cooperar num projeto científico, conseguem coordenar-se, mesmo tendo pontos de vista diferentes; neste processo, cada uma das partes mantém a sua identidade, as suas questões e pode realizar os seus trabalhos mantendo, no entanto, a articulação com os outros. Neste artigo original, trata-se de uma cooperação durável (1907-1939) entre atores extremamente diversos (investigadores, administrativos, gestores, naturalistas amadores, taxidermistas, fundações, políticos) em torno da construção de um museu de zoologia na Universidade da Califórnia. As soluções inventadas pelos atores em situação são de duas ordens : uma relativa estandardização dos métodos (não em função apenas das exigências científicas, mas após um processo de "reconciliação" entre os interesses dos diferentes atores) e o desenvolvimento de objetos-fronteira. A noção de objetofronteira é

\footnotetext{
"um conceito analítico dos objetos científicos que ao mesmo tempo fazem parte de diversos mundos sociais que se cruzam e satisfazem os requisitos informacionais de cada um deles. Objetos-fronteira são objetos que são ao mesmo tempo flexíveis o suficiente para se adaptarem às necessidades locais e aos constrangimentos das diversas partes que os empregam, mas também robustos o suficiente para manter uma identidade comum nos diversos locais [...] Possuem diferentes significados em diferentes mundos sociais mas a sua estrutura é suficientemente comum a mais do que um mundo, o que os torna reconhecíveis, um meio de translação. A criação e gestão de objetos-fronteira é um processo chave no desenvolvimento e manutenção da coerência através do cruzamento de mundos sociais" (supra citado, p. 393)
}

Com a noção de objeto-fronteira, trata-se "de entrar na mecânica das associações em si mesma e na forma como elas suportam a tensão entre cooperação e heterogeneidade" (Trompette \& Vinck, 2009, p. 9). Nesta perspetiva, o termo fronteira não é visto como um limite de território mas antes como "um espaço partilhado, o lugar preciso onde o sentido de aqui e ali se juntam. Estes objetos comuns constituem fronteiras entre grupos graças à flexibilidade e à estrutura partilhada ; eles são ingredientes da ação". (Star, 2010, p. 20). Quanto aos "objetos", eles podem ser materiais ou imateriais ; sendo 
definidos não pelas suas características intrínsecas, mas fazendo referência à ação e cooperação². É devido ao facto de se tratar de fazer coisas juntos, de trabalhar num projeto comum, que estes objetos são construídos no encontro de atores provenientes de comunidades de prática diferentes. Eles são pertinentes para a ação no âmbito do projeto comum, mas são também mobilizados para fins próprios a cada um dos atores, nas suas práticas respetivas, mesmo que estas não sejam interdisciplinares.

Entre as propriedades dos objetos-fronteira, houve um forte investimento na "flexibilidade interpretativa", um "mesmo" objeto pode ter um sentido diferente consoante a utilização e interpretação que é feita por aqueles que a ele se referem. Entretanto, certas dimensões da noção original são frequentemente esquecidas, nomeadamente a de "infraestrutura invisível para a qual os objetos-fronteira contribuem através das convenções e padrões que eles veiculam" (Trompette \& Vinck, 2010, p. 11) (ver também Bowker \& Star, 1999).

Retivemos esta noção para refletir sobre o dispositivo EVREST visto que ela permite pensar de modo indissociável as formas da construção comum (objetos e infraestrutura) e a tensão - inerente ao dispositivo - entre a perspetiva de um projeto comum e a heterogeneidade dos atores e das práticas, e de estar atento às "intersecções" através da exigência de consensos. No presente artigo, daremos ênfase sobretudo à dinâmica da cooperação entre investigadores e médicos do trabalho e a forma como ela influenciou o modo de construção e as formas do dispositivo. 0 nosso próprio posicionamento, mas também a juventude do dispositivo não nos permitem desenvolver uma análise fina do uso do EVREST nas práticas dos médicos do trabalho no seio das empresas e dos efeitos da quantificação no domínio da saúde no trabalho nas empresas. Contudo, o EVREST é objeto de uma parte duma tese de sociologia em curso $^{3}$ sobre as práticas e os efeitos sociais da quantificação no âmbito da saúde no trabalho, no seio de grandes empresas. Uma parte dos trabalhos conduzidos neste contexto contribuíram para alimentar a nossa própria reflexão sobre o EVREST.

\subsection{O berço do nascimento do EVREST}

11 O contexto do nascimento do EVREST numa grande empresa aeronáutica (Gilles, 2006 ; Gilles \& Volkoff, 2009) contribuiu para lhe proporcionar certas características. A génese do EVREST nesta empresa está muito associada às preocupações trazidas por uma médica do trabalho e ergónoma, que tinha estado na origem da criação (em 1985) de um departamento de ergonomia, passando depois a liderar o departamento dos fatores humanos no seio da direção geral. A empresa viu-se confrontada com dificuldades após a colocação em prática de medidas de idade, que demonstraram os desafios ligados ao risco de perda de competências essenciais, num domínio caracterizado pela tecnologia muito avançada e onde a fiabilidade é imperativa. Foi então desencadeada toda uma démarche, visando entre outros, com o objetivo de construir indicadores para que os responsáveis de produção e dos recursos humanos pudessem ter em conta os saberes e os saberes-fazer dos operadores (Doppler, 1995). Esta démarche constituiu também uma ocasião para que a ergonomia pudesse penetrar no universo da conceção, assim como tentar retirar as questões da saúde de uma visão bastante reduzida da prevenção ("longe de se confinar à exclusão do risco de patologias, procurou favorecer a visão da saúde como um processo de desenvolvimento" [Doppler, 2004]). Esta démarche foi construída apoiando-se em relações estreitas e cooperações com os investigadores do 
ramo da ergonomia, investigadores com os quais as ligações foram criadas no momento da formação em ergonomia desta responsável de empresa (Falzon \& Doppler, 1998).

Alguns elementos que permitiam a reflexão sobre as relações entre as mudanças técnicas e organizacionais e as características do trabalho e da população (em particular da idade e antiguidade) foram introduzidos em diferentes etapas de vários projetos de conceção ou de melhoria. Tratava-se igualmente de mostrar que a análise da atividade pode enriquecer as estratégias de conceção, fornecendo elementos sobre a variabilidade das situações reais de trabalho. Estas preocupações foram integradas na formação dos conceptores e completadas por parâmetros sobre as características do funcionamento humano. Foi também dada ênfase à necessidade de uma análise que integrasse a dimensão temporal dos fenómenos, bem como algo particularmente importante como "ter em conta e explicitar a experiência profissional passada (dos operadores), o seu saber-fazer. É necessário poder integrar o passado para se poder projetar o futuro (...) A dimensão histórica é uma característica essencial da dinâmica do funcionamento humano que, por várias vezes, é esquecido no mundo empresarial" (Doppler, 1995, p. 422). Encontrar-se-á no EVREST o critério da idade e esta dimensão dinâmica para introduzir uma reflexão mais abrangente sobre as relações entre a saúde e o trabalho.

13 Finalmente, para penetrar no universo dos conceptores, criar "uma ponte entre o mundo técnico e o dos recursos humanos" (Falzon \& Doppler, supra citado), teve início uma reflexão sobre a possibilidade de se introduzir indicadores que retomassem estas preocupações nos painéis de controlo, usados habitualmente pelos decisores da empresa. Tendo pouco a pouco a ideia que os médicos do trabalho poderiam dar o seu contributo, "desenvolvendo uma abordagem coletiva e trazendo aos decisores, aos parceiros sociais, dados numéricos sobre as relações entre saúde e trabalho" (extrato de um relato de um grupo de trabalho interno).

Do lado dos médicos do trabalho das empresas, a quantificação aparece como um recurso para tornar visíveis as questões da saúde nas suas relações com o trabalho, mas também a sua própria atividade e utilidade. Eles têm esperança que estes novos "indicadores" possam contribuir para transformar as representações e abrir novos espaços de debate sobre as questões de saúde no trabalho, espaços nos quais os seus pontos de vista serão mais valorizados.

15 Estas preocupações vão ao encontro das dos investigadores do CREAPT (Centre de Recherches et d'Études sur l'Âge et les Populations au Travail ${ }^{4}$ ), com o qual uma parceria foi iniciada sobre a temática da idade e do trabalho, em torno de estudos ergonómicos e demográficos no seio da empresa (Millanvoye \& Colombel, 1996) e que tinham, eles mesmos, um percurso profissional marcado por uma reflexão e uma prática sobre a quantificação nos domínios do trabalho e da saúde.

16 Neste reencontro forjou-se um primeiro dispositivo EVREST (Archambault et al., 2006) cujas grandes características persistem atualmente :

- um dispositivo construído gradualmente em colaboração com os investigadores

- um dispositivo ancorado na prática dos médicos do trabalho e apoiado por eles

- um dispositivo concebido para ser duradouro - ou seja, mais ligeiro e "generalista" que um questionário pontual sobre um problema particular

- um dispositivo para produzir "indicadores" tanto sobre o trabalho como sobre a saúde e suas evoluções

- um dispositivo que possa fazer eco às preocupações da ergonomia da atividade 
17 Este dispositivo foi retomado e adaptado com o objetivo de poder ser utilizado pelos médicos do trabalho de serviços interempresas (ou seja, para várias pequenas empresas) e outros serviços autónomos.

\subsection{Um dispositivo que vai "interessar" mais do que uma empresa}

O dispositivo nacional EVREST surge do encontro entre os investigadores que tinham participado na criação do dispositivo nessa grande empresa aeronáutica e médicos do trabalho de serviços interempresas. Estes médicos do trabalho, reunidos num "grupo Epidemiologia" no seio do Cisme ${ }^{5}$ tinham, a grande maioria deles, uma certa apetência para as abordagens quantitativas, uma formação em epidemiologia e uma prática comum de questionários pontuais sobre diversos assuntos. $\mathrm{O}$ encontro deu-se por ocasião de uma reflexão deste grupo de médicos sobre as questões de trabalho e saúde no final da vida ativa. Eles quiseram fazer apelo a investigadores conhecidos, por um lado, pelos seus trabalhos no âmbito do envelhecimento no trabalho, mas também pela sua experiência com questionários neste domínio, conjuntamente com os médicos do trabalho (Derriennic, Touranchet \& Volkoff, 1992, Coutrot \& Molinié, 2006, Molinié \& Volkoff, 2000). Durante os intercâmbios que tiveram lugar em torno deste projeto, e mais tarde no âmbito da concretização com o questionário saúde e vida profissional depois dos 50 anos (SVP50), inúmeras mudanças ocorreram no seio deste grupo : uma conexão mais importante com a esfera da estatística pública (exame de diversos questionários para analisar as questões utilizadas) e debates sociais a nível nacional (nomeadamente através do Conselho de orientação das reformas - que financiou o inquérito SVP50), a emergência de preocupações ligadas ao universo da investigação (revisão bibliográfica num campo de conhecimentos, participação em colóquios, publicações científicas, etc.), um aprofundamento da reflexão sobre o lugar da quantificação no domínio da saúde no trabalho e na prática clínica dos médicos do trabalho, etc. A sua reflexão sobre a quantificação conduziu estes médicos a ter um grande interesse pela experiência do observatório em saúde no trabalho no seio da empresa de construção aeronáutica, que estava bem em ressonância com as preocupações que eles tinham já partilhado no seio do grupo, mas com o desejo de refletir sobre a especificidade da sua prática e do acompanhamento dos trabalhadores das empresas mais pequenas e de sectores diversificados.

\section{Preocupações partilhadas}

19 Um processo de co-construção entre atores provenientes de mundos profissionais diferentes não obriga a que tenha sido estabelecido um consenso previamente. No entanto, é necessário que exista um certo número de preocupações partilhadas que intensifiquem a vontade de realizar um trabalho conjunto - e duradouro - em torno de um projeto e que se criem modalidades de partilha que permitam não só uma construção comum, como a preservação das especificidades. Evocaremos algumas preocupações partilhadas que tornaram possível a criação e o desenvolvimento do EVREST, ainda que seja provável que as ponderações entre estas diferentes preocupações difiram de acordo com as pessoas que integram o projeto. 


\subsection{A afirmação de um interesse pela quantificação pelas redes de atores da saúde no trabalho}

Tanto para os médicos como para os investigadores, o uso da quantificação parecia apresentar vários interesses no contexto das evoluções do trabalho. 0 primeiro está ligado à persistência, nos países industrializados e em França em particular, de um nível elevado de constrangimentos e danos no trabalho, fator importante de desigualdades sociais de saúde e pouco tidas em consideração nas políticas públicas e nas negociações sociais, (Arnaudo et al., 2004, Bué et al., 2007, Gollac \& Volkoff, 2007). Os números têm o interesse de vir reforçar, dando-lhes o lastro do peso da quantificação, uma série de constatações que recorda, por exemplo, que a "penosidade" do trabalho não é apenas a história antiga, ou que as questões de saúde não sejam independentes do que se passa no trabalho. Um segundo interesse pode ser posto em relação com a tendência de intensificação do trabalho, percetível depois de duas décadas (Askenazy et al., 2006). Os seus efeitos sobre a saúde, por vezes indiretos, variam de pessoa para pessoa e são frequentemente associados às experiências individuais - o que dificulta a visibilidade da ligação entre o trabalho e a saúde (Volkoff, 2008). A quantificação pode ser uma das vias que permita sair da crescente individualização das ligações saúde/ trabalho. Finalmente, para revelar estas dificuldades, fornecer os elementos de apreciação, e contribuir para abrir possibilidades de transformação, os médicos do trabalho podem (ou poderiam) ter um papel maior. Ora, a quantificação é também uma "encruzilhada de idiomas" (Desrosières, 1993) que pode ajudar a valorizar as preocupações nas esferas de discussão ou de decisão nas quais, muito frequentemente, aquilo que não é quantificado, não existe.

21 Os atores em causa partilham igualmente a convicção de que os indicadores aos quais nos referimos habitualmente na empresa quando falamos de saúde no trabalho são de fraca utilidade para sustentar estas preocupações. Efetivamente, as estatísticas de acidentes de trabalho e de doenças profissionais constituem a base essencial das avaliações estatísticas em saúde no trabalho na empresa, ora apresentam-se como ferramentas de medida ainda que estejam inteiramente imbricados nas práticas de gestão dos riscos e da compensação. Trata-se de um exemplo daquilo a que Desrosières (2004) chama de "circularidade" entre os dados e que permite avaliar um facto social e os instrumentos escolhidos para agir sobre a sua evolução. Quanto aos indicadores provenientes dos relatórios anuais fornecidos pelos médicos do trabalho, eles têm mais como alvo a atividade implementada (visitas médicas, atos paramédicos, atividades terceirizadas, etc.) do que a saúde no trabalho.

Daí a ideia de encontrar um dispositivo, ancorado na prática dos médicos do trabalho, que favoreça a visibilidade de uma pluralidade de dimensões do trabalho e da saúde, que permita um acompanhamento para analisar as relações de médio e longo-termo, e que possa fornecer conhecimentos úteis à prevenção, ou de forma mais abrangente à transformação das situações de trabalho, através da articulação com as práticas de diferentes atores nestes domínios e reforçando o seu poder de convicção. 


\subsection{Um "modelo" partilhado das relações entre o trabalho e a saúde}

23 Talvez pelo facto de terem sido confrontados com questões de idade e de percursos profissionais, bem como por terem trabalhado em conjunto, os médicos do trabalho e os investigadores que conceberam o dispositivo nacional EVREST escolheram abordar as questões da saúde no trabalho sem antecipar o sentido das relações causais entre estes dois termos e inscrevendo-os numa perspetiva diacrónica. Efetivamente, sem minimizar a sua importância - e a grande ignorância - dos danos causados na saúde que têm origem nas condições de realização do trabalho, eles não têm como objetivo tratar as relações saúde-trabalho unicamente no registo da alteração, da degradação ou da fragilização da saúde pelo trabalho. Uma tal orientação teria deixado esquecida a forma como a saúde tem impacto sobre e na vida profissional e o papel importante do trabalho na construção e desenvolvimento da saúde.

A interrogação sobre o trabalho não visa unicamente identificar "exposições", ainda que ela inclua algumas questões sobre esta temática. Esta noção, valiosa em epidemiologia, deixa, no entanto " supor que os operadores são passivos num ambiente de riscos" (Laville, 1998, p. 154). A ergonomia mostra que os operadores agem sobre as suas "condições de trabalho", nomeadamente para preservar ou construir a sua saúde ; estas estratégias são mais ou menos possíveis, limitadas, eficientes, de acordo com as margens de manobra de que eles dispõem. Nesta perspetiva, um questionário baseado sobre as respostas dos trabalhadores pode apresentar qualidade de integração, "as respostas dos operadores traduzem alternadamente uma combinação de constrangimentos e o espaço disponível para as suas próprias estratégias de preservação" (Volkoff, 2005, p. 29-30). Através do questionário EVREST, visamos menos isolar as características do trabalho na origem de um ou outro problema de saúde do que alimentar uma estratégia exploratória, compreensiva, que tenta considerar várias dimensões numa situação, identificar configurações das relações entre os aspetos do trabalho e os da saúde. Para além disso, o carácter longitudinal do dispositivo permite considerar instruir as relações tendo em conta não apenas as características do trabalho concomitantes com as da saúde, mas também as suas respetivas evoluções.

Para além de detetar algumas formas de "penosidade" do trabalho (constrangimentos de horários de trabalho, penosidade física), a interrogação sobre o trabalho proposta pelo EVREST pretende estar igualmente atenta à maneira como os trabalhadores podem encontrar (ou procurar) no trabalho recursos para o desenvolvimento da sua saúde. 0 trabalho é também abordado sob o ângulo do reconhecimento, da cooperação, da possibilidade de fazer um trabalho de qualidade, de oportunidades de receber ou dar formação. O questionário permite examinar - pelo menos de forma sumária - a maioria das dimensões consideradas como constitutivas de "fatores psicossociais de risco" ${ }^{\text {: as }}$ exigências do trabalho (nomeadamente a pressão temporal), a autonomia e as margens de manobra (nomeadamente: poder escolher a forma de proceder, ter um trabalho que permita a aprendizagem), os conflitos de valor (ter os meios necessários para realizar um trabalho de qualidade, ter de fazer coisas que desaprovamos - questão introduzida em 2011), certos aspetos do apoio social e do reconhecimento no trabalho (ter possibilidades suficientes de entreajuda, de cooperação, trabalho reconhecido pelo círculo profissional) ou exigências emocionais (trabalho em contacto com o público) e, por último, a insegurança do trabalho e do emprego (trabalhar com medo de perder o emprego - questão introduzida em 2011). Tendo em mente a ideia de que não se trata apenas de identificar os "riscos", 
mas também do interesse pelas condições que permitem a alguns trabalhadores se sentir melhor no seu trabalho, pelo menos durante um certo período, pelo menos para um ou outro aspeto do seu trabalho, e que, por vezes, as ações úteis podem visar a preservação de certos elementos das situações de trabalho e não apenas a suprimir os danos.

$\mathrm{Na}$ abordagem da saúde que foi utilizada, foi imediatamente descartada uma aproximação pelas patologias, mesmo se a questão do trabalho com uma doença crónica está, indubitavelmente, cada vez mais presente nas empresas e nas preocupações dos médicos do trabalho ${ }^{7}$; contudo, ela necessita provavelmente de uma investigação específica de outra natureza. No entanto, muitas patologias conduzem ainda à exclusão do emprego, enquanto os problemas de saúde de ordem infrapatológica se revelam mais compatíveis com a manutenção da atividade profissional, pelo menos sob determinadas condições. Para cada dimensão da saúde (cardiorrespiratória, neuropsíquica, osteoarticular, etc.) os indicadores existentes no EVREST são de três ordens : a primeira referente à existência de sinais e sintomas, tenham eles sido ou não validados por diagnósticos médicos; a segunda referente às interrogações sobre os incómodos eventuais no trabalho associados a esse problema de saúde e, por último, a terceira referente aos tratamentos e cuidados existentes.

A noção de incómodo no trabalho associada a um problema de saúde, tinha já sido introduzida no questionário SVP50, uma vez que surgiu a ideia de que não era suficiente interessar-se pelo estado de saúde (mesmo percebido pelo trabalhador) para deduzir as dificuldades que este pode gerar na realização da atividade (Molinié, 2006a e b). Estas dificuldades reenviavam para a natureza e severidade dos problemas de saúde, às limitações funcionais mais ou menos importantes que daí poderiam resultar, mas também aos recursos individuais e coletivos que poderiam ser mobilizados para lhes fazer face e às características do trabalho e da sua organização (constrangimentos temporais, entreajuda, margens de manobra, ...). Podemos aproximar esta preocupação das, mais antigas, que conduziram a evoluções conceptuais no campo da deficiência para sair do modelo biomédico e propor conceitos pertinentes para o intercâmbio e intervenção dos profissionais (Nagi, 1964, Wood, 1975, World Health Organization, 1980, Minaire, 1992, Fougeyrollas, 2002). Várias noções foram distinguidas: o que está associado à doença ou à deficiência, as limitações funcionais, as restrições de atividade, e a "deficiência contextual" ou "desvantagem social". A distinção entre limitação funcional e restrição de atividade (ou mesmo deficiência contextual) permitiu lançar interrogações relativas a estratégias de compensação, individuais ou coletivas, aos recursos que as pessoas dispõem (ou podem dispor) para fazer face a estas limitações e às características e constrangimentos do ambiente. A introdução da noção de incómodo no trabalho, da mesma forma, abre provavelmente um espaço de reflexão que pode "desmedicalizar" a questão da saúde no trabalho, permitindo, por um lado voltar a dar um lugar à experiência que as pessoas foram construindo e que integra a experiência das suas próprias deficiências e, por outro lado, interrogar sobre os recursos que podem ser encontrados ou construídos na situações de trabalho para limitar os incómodos. Estas questões são igualmente interessantes numa perspetiva longitudinal, na medida em que elas permitam evocar sinais precoces, alertando para a possibilidade de evitar certas degradações ulteriores da saúde em relação com o trabalho e uma eventual desinserção profissional. 


\subsection{Uma abordagem que repousa sobre as avaliações dos trabalhadores assalariados}

\section{trabalhadores no momento dos inquéritos nacionais sobre as condições de trabalho} (Gollac, 1997) ou do inquérito ESTEV (Santé, travail et vieillissement ${ }^{9}$ ) (Molinié, 2003, supra citado). As respostas espontâneas dos trabalhadores podem refletir uma visão redutora da sua atividade e das suas condições de trabalho se não for feita uma elucidação aprofundada juntamente com eles (Teiger \& Laville, 1991). Por outro lado, todo o questionário, toda a ficha de recolha de dados, são "dirigidas" e as respostas dependem das representações que os trabalhadores têm das expectativas e objetivos do destinatário ou patrocinador (poderes públicos, empregadores, hierarquia, sindicatos, ...). Estas respostas vão igualmente flutuar de acordo com o humor do dia e os eventos recentes. A mais longo-prazo, eles serão influenciados pelos processos sociais, que determinam a visibilidade das condições de trabalho de um dado meio (Gollac, supra citado). Mais problemático para certas análises em saúde no trabalho: as respostas sobre um aspeto do trabalho podem estar dependentes do estado de saúde. Assim, as dores nas costas reforçam as apreciações negativas sobre a manutenção de posturas difíceis, muito mais do que os esforços a realizar (Duquette et al, 1997, Bologh et al., 2004). Finalmente, as apreciações dos trabalhadores podem igualmente refletir ignorâncias, ou mesmo estratégias defensivas (Dejours, 1993). No entanto, sobre certas questões, a perceção que as pessoas têm está em relação direta com a sua atividade. Então, como o recorda Michel Gollac (supra citado), é suficiente que um trabalhador se veja obrigado a responder a um pedido, ou se sinta obrigado a ser mais rápido para que isto tenha um efeito real sobre o seu ritmo de trabalho.

A formulação das perguntas do EVREST retoma frequentemente a que foi utilizada em inquéritos nacionais cuja qualidade é reconhecida, o que permite beneficiar do capital da reflexão sobre o sentido e uso destas questões, de um reconhecimento da sua pertinência e de abrir a possibilidade de comparações externas - mesmo que seja certo que as respostas a uma questão não dependem apenas da formulação da mesma, mas também do âmbito do inquérito no qual se inserem, de quem as propõe e dos seus objetivos.

31 No âmbito do EVREST, o lugar do discurso do trabalhador é tão importante que é o médico que o recolhe e é no intercâmbio que se pode desenvolver a partir do EVREST que se constrói igualmente o sentido dos "dados". Se, na maioria dos casos, o trabalhador preenche sozinho a parte consagrada ao trabalho (tendo o questionário lhe sido sugerido antes da entrada no gabinete médico), as suas respostas dão, em seguida, lugar à discussão com o médico, nomeadamente quando as respostas lhe parecem surpreendentes. Esta situação não é excecional e o médico do trabalho pode utilizá-la para aceder a uma melhor compreensão das questões da saúde no trabalho, processos 
que não permitem a recolha através de um entrevistador externo. O EVREST pode, então, facilitar o intercâmbio com determinados trabalhadores assalariados que se exprimem muito raras vezes, solicitando de forma diferenciada o discurso dos silenciosos, dos discretos que não ousam ou não sabem expressar o que vivem ou sentem no trabalho. A participação do médico na construção de informação sob o formato de número, a qualidade da sua escuta, o conjunto dos elementos que utiliza para construir um "ponto de vista" sobre as questões da saúde no trabalho neste contexto preciso são igualmente o que lhe permitirá trazer os resultados para o debate, enriquecendo-o e confrontando-os com outras abordagens e outros pontos de vista. A escolha de um questionário muito curto é também coerente com esta preocupação de não conferir aos dados numéricos a autoridade da prova e de os inserir numa abordagem com uma mais larga compreensão, integrando elementos provenientes da clínica médica.

\section{Uma "infraestrutura" comum para usos diversificados}

O EVREST é, tal como já foi referido, um dispositivo que surgiu através da colaboração entre atores com profissões diferentes que aceitaram participar voluntariamente. A sua construção inscreve-se num processo que visa tornar compatíveis as exigências próprias de cada um destes "mundos" profissionais. Ela passa pela criação e partilha de "objetos", partilha na qual cada um "encontra a sua conta", mas também através da elaboração progressiva de novas formas de coordenação e de intercâmbio. 0 dispositivo permanece graças ao facto de que os que nele participam encontram e encontrarão nele um interesse, mesmo que a criação de uma "infraestrutura" procura assegurar uma relativa perenidade e estabilidade ao dispositivo. Apresentaremos de seguida as grandes características do dispositivo, tanto como quadro formal que foi construído por e para estas colaborações, como o que pode materializar diferentes formas de utilizar estes objetos, diferentes maneiras dos atores atribuírem importância a estes objetos. Nesta perspetiva, examinaremos vários aspetos do EVREST: o questionário (cujo conteúdo já foi descrito anteriormente) e a amostragem, o dispositivo "técnico", o dispositivo "organizacional" - numa tentativa de mostrar sempre como é que visam criar uma "infraestrutura" comum ao abrir a possibilidade de usos diversificados. Isto é, o que faz com que os possamos considerar como "objetos-fronteira".

\subsection{O questionário EVREST : um quadro comum e questões "livres"}

O questionário EVREST é a pedra angular do dispositivo. Sendo suporte de alimentação da base de dados que pode ser utilizável para os trabalhos de natureza científica, ele constitui assim uma trama de intercâmbios entre o médico do trabalho e os trabalhadores assalariados e um dos suportes dos médicos do trabalho, sozinhos ou não, para dar a conhecer um "cenário" das condições de trabalho de uma empresa ou de uma situação profissional e trazer para a discussão as questões da saúde no trabalho neste contexto. É também um objeto partilhado que pode permitir o intercâmbio entre pessoas implicadas na rede EVREST a vários níveis, e entre esta rede e outros interlocutores interessados por estas questões, tanto no campo científico como no da intervenção pública ou privada, no plano nacional, regional ou local. Estas múltiplas 
facetas conduziram à reflexão, evidentemente, ao conteúdo do questionário e ao seu tamanho, ao seu modo de utilização, mas também à sua pertinência e aos seus limites para uma investigação no terreno e à sua pertinência científica (ver mais acima os pontos 2.2 e 2.3), assim como a forma de considerar aquilo que estava em jogo no conjunto destas dimensões. Deve igualmente permanecer relativamente estável para permitir análises diacrónicas, ou mesmo longitudinais.

entanto, o dispositivo é também concebido para permitir usos específicos do EVREST em função das necessidades dos médicos. Com o objetivo de incluir questões mais específicas e pertinentes para uma população particular ou sobre um assunto em particular, o questionário EVREST inclui zonas "livres", cuja existência foi prevista no questionário e dá acesso a um campo de introdução na base de dados, embora o seu conteúdo seja definido por aqueles que o preenchem. Apenas os médicos que decidem utilizar estas zonas conseguem saber a que corresponde o que foi introduzido e analisar as informações correspondentes. A partir de 2011, a parte referentes a essas zonas "livres" foi francamente aumentada no questionário, com duas zonas no início do mesmo, tendo como objetivo identificar por exemplo oficinas ou profissões específicas, uma zona que permitisse introduzir uma "exposição" não repertoriada a priori, uma questão "livre" sobre cada item de saúde e, sobretudo, juntar dez questões totalmente "livres" no final do questionário.

Esta importante evolução assinala bem o projeto do EVREST, que não pretende ser um dispositivo nacional que uniformiza e "utiliza" os médicos do trabalho como entrevistadores altamente qualificados, mas um dispositivo partilhado que os médicos podem construir maioritariamente " a seu gosto", em função das suas preocupações locais - mas sem esquecer de contribuir para a viabilidade de análises nacionais. Não sabemos ainda qual será o uso dado a estas zonas "livres", que apenas cresceram com as mudanças introduzidas em 2011. As primeiras investigações sobre esta temática parecem indicar que elas são sobretudo utilizados por redes de médicos que acordam a utilização de certas questões no protocolo (nas dez questões "livres") no seio de uma grande empresa, ou de uma região, seja para um inquérito pontual (durante um ano ou alguns meses), seja com uma perspetiva coordenada de investigação mais duradoura.

\subsection{A amostragem : os nascidos em "Outubro de anos pares" e os outros}

Estas formas de adaptação do questionário às suas necessidades são geralmente combinadas com a escolha do alargamento da amostragem pelos médicos. Todo o médico do trabalho que aceitou voluntariamente participar no EVREST compromete-se a interrogar (pelo menos) todos os trabalhadores assalariados nascidos em Outubro dos anos pares que ele vê em consulta sistemática, o que constitui uma carga de trabalho que não é demasiado pesada. Estes trabalhadores constituem a amostra nacional, que dá lugar às explorações nacionais e regionais e sobre a qual se baseiam os trabalhos científicos pelos quais os investigadores são responsáveis. No entanto, cada médico pode igualmente, se o desejar, alargar a sua utilização do dispositivo, sozinho ou com colegas, com o objetivo de recolher os dados de forma mais sistemática para uma empresa, um sector profissional, uma profissão... Ele pode, então, adaptar a amostragem em função do nível que ele pretende atingir, até utilizar, por exemplo, todos os trabalhadores de uma mesma empresa. 
37 Não é ainda possível fazer um balanço destes usos particulares, que não dão lugar a uma centralização sistemática, mas podem ser conhecidos a partir do momento em que o médico referenciador de uma região seja informado, ou quando o apoio de um estatístico da rede regional tenha sido solicitado ${ }^{10}$. Podemos então constatar que os médicos se inserem frequentemente de forma gradual no dispositivo: começam por interrogar apenas os trabalhadores nascidos em Outubro dos anos pares, o que lhes permite a familiarização com o questionário, o dispositivo de introdução e de começar a organizar-se no seio do serviço de saúde no trabalho para integrar o EVREST na atividade quotidiana (deteção dos trabalhadores nascidos em Outubro de anos pares, preparação do questionário, organização da utilização, articulação com o dossier em papel, introdução dos dados, etc.). Posteriormente, apenas certos médicos se comprometem numa utilização mais específica do EVREST numa empresa ou num sector de atividade. De acordo com os nossos conhecimentos, isto dizia respeito a cerca de 200 médicos em finais de 2010. 0 quadro no parágrafo 3.4 demonstra bem o aumento progressivo do número e da parte das fichas "fora da amostragem nacional", associadas a estes usos específicos, à medida que o dispositivo se desenvolve.

\subsection{Os aspetos técnicos : permitir explorações nacionais mas também dar a cada médico a possibilidade de analisar os seus próprios dados}

O dispositivo técnico foi então concebido, por um lado, para usos científicos a partir das explorações da amostra nacional e também para usos diversificados pelos médicos utilizadores. Isto traduz-se por diferentes possibilidades de acesso e recuperação dos dados : os investigadores da equipa do projeto nacional têm um acesso ao conjunto dos dados da amostra nacional ${ }^{11}$, os médicos referenciadores regionais acedem a estes mesmos dados mas apenas para a sua própria região. Quanto aos médicos participantes, cada um deles tem acesso, via internet, a um sítio seguro no qual podem introduzir mas também recuperar o conjunto dos dados introduzidos (incluídos ou não na amostra nacional). Todas as operações conduzidas a outros níveis (serviço, sector, profissão, etc...) supõem a partilha dos dados respetivos referentes a este campo de estudo pelos médicos implicados.

Um sítio público de informação (http://evrest.istnf.fr), distinto do sítio de introdução de dados, coloca à disposição as ferramentas necessárias ao funcionamento do dispositivo (questionário, guia de preenchimento, nomenclaturas, protocolos, etc.). No entanto, ele fornece também a cada médico um programa automático de produção de resultados simples, sobre a forma de um documento utilizando o questionário tendo, para cada questão, os resultados que concernem a população inquirida por este médico. $\mathrm{O}$ médico pode ter igualmente à disposição, com a frequência que desejar, resultados simples para o conjunto dos trabalhadores assalariados que ele entrevistou ou para um subconjunto que ele queira selecionar (uma empresa, por exemplo). Ele pode também encontrar no sítio diversas ferramentas (slides ajustáveis) que facilitam a apresentação dos resultados.

$\mathrm{O}$ sítio de informação permite igualmente responder às questões (sob a forma de $\mathrm{FAQ}$ ) ligadas à utilização e evolução do dispositivo, e dá acesso aos resultados provenientes das explorações da base nacional, aos níveis nacional e regional. Ele coloca, finalmente, 
à disposição reflexões e experiências em torno de diferentes usos do EVREST e, de forma mais abrangente, os números em saúde no trabalho.

41 Estes elementos "técnicos" permitem então fornecer a cada médico ferramentas que facilitem um uso personalizado do EVREST, constituindo um local de intercâmbio de informações e de experiências, mas também colocando à disposição de todos os resultados por sector, profissão, etc. (havendo efetivos suficientes), permitindo escolher eventuais "referências" para comparação com os resultados locais.

Um modo de organização original : formas diversas de parcerias e redes, a diferentes níveis

43 O dispositivo foi acionado, progressivamente, desde 1 de janeiro de 2007, data na qual ele arrancou a título experimental numa região francesa (o Nord-Pas-de-Calais). Com a abertura a nível nacional a partir de 2008, do sítio de informações e de um sítio para a inscrição dos médicos e introdução dos dados, o dispositivo pôde arrancar noutras regiões. No entanto, o seu desenvolvimento é bastante progressivo, visto que a possibilidade de inscrição no EVREST depende da existência do início de estruturação ao nível regional, estrutura que só pode ser colocada em prática através da iniciativa dos médicos da região - e não da equipa nacional (cf. o texto seguinte)

44 A 1 de julho de 2011, 1229 médicos do trabalho estavam inscritos no EVREST (mas nem todos introduziram fichas de trabalhadores). A base nacional (trabalhadores assalariados nascidos em Outubro de anos pares) era constituída por cerca de 10800 fichas em 2008, mais de 13900 em 2009 e cerca de 12300 em 2010.

\begin{tabular}{|l|l|l|l|l|l|}
\hline Número de fichas* introduzidas & $\begin{array}{l}2007 \\
\text { (experimentação) }\end{array}$ & 2008 & 2009 & 2010 & Total \\
\hline $\begin{array}{l}\text { Fichas da amostra nacional (Outubro dos anos } \\
\text { pares) }\end{array}$ & 2503 & 10805 & 13914 & 12277 & 39499 \\
\hline $\begin{array}{l}\text { Fichas fora da amostra nacional (ligadas a usos } \\
\text { específicos) }\end{array}$ & 4806 & 15172 & 18169 & 22250 & 60397 \\
\hline Total de fichas introduzido & 7309 & 25977 & 32083 & 34527 & 99896 \\
\hline
\end{tabular}

* uma ficha corresponde a um questionário por trabalhador no âmbito de uma consulta onde tinha sido utilizado o EVREST

o dispositivo é caracterizado por três grandes níveis de funcionamento: o nível nacional, o nível regional e os médicos participantes. A cada um destes níveis estão associadas formas de intercâmbios e de parcerias plurais em torno do EVREST e que mereciam ser analisadas mais aprofundadamente do que aquilo que nós próprios podemos fazer.

O nível nacional é, desde 2009, estruturado em torno de um "groupement d'intérêt scientifique"12 (GIS EVREST), que associa vários organismos públicos ou de investigação que se interessam pela melhoria das condições de trabalho e pela saúde no trabalho, o organismo que coordena os serviços interempresas de medicina no trabalho e a empresa aeronáutica onde o EVREST foi criado $^{13}$. A criação deste GIS estabiliza a existência do dispositivo, ao dar-lhe uma melhor visibilidade institucional, assegurando 
financiamentos para o funcionamento e reforçando os seus objetivos científicos. Um conselho científico, composto por seis personalidades de diferentes disciplinas ${ }^{14}$ fornece a sua análise crítica e um suporte nas reflexões. Este GIS materializa igualmente a necessidade sentida, para fazer existir este dispositivo, de conseguir o seu reconhecimento por diferentes "aliados" entre os parceiros públicos e de investigação, cujos interesses podem integrar o que está em jogo no dispositivo EVREST. Sobre este ponto, podemos ainda relacionar a démarche daquela que foi descrita por Star e Griesemer a propósito das alianças que foram feitas em torno da criação do museu de zoologia e dos objetos-fronteira que se tornaram o suporte destes encontros entre universos profissionais.

o funcionamento do nível nacional repousa principalmente na diretora do GIS (coautora do presente artigo) e sobre os membros de uma equipa de projeto (Equipa projeto nacional EVREST) que junta médicos do trabalho, investigadores em saúde no trabalho e estatísticos. Eles são responsáveis pela implementação do dispositivo, da sua evolução, e de alimentar e animar a reflexão do conjunto dos médicos participantes em torno do uso dos números em saúde no trabalho. Eles são igualmente responsáveis pela constituição, a gestão e a exploração da amostra nacional. Eles detêm a responsabilidade da animação da rede dos médicos referenciadores regionais que fazem a ligação entre os três níveis de funcionamento do EVREST. Esta equipa de projeto, ainda muito fortemente composta por aqueles que construíram o dispositivo EVREST, é o lugar central onde se tecem os compromissos, onde se negoceiam as evoluções do dispositivo, onde se preparam as discussões da rede e das instâncias de direção do GIS. A maioria dos médicos que aqui participam são igualmente referenciadores para a sua região.

O dispositivo EVREST tem uma ancoragem regional forte. Efetivamente, ele só funciona havendo médicos referenciadores que sejam voluntários na região, que permitam aos médicos da região participar, visto que toda a inscrição de um médico que queira participar no EVREST supõe um intercâmbio e uma validação pelo médico referenciador da sua região. Não havendo um médico referenciador, nenhum médico da região se pode inscrever - ou seja, ter o seu utilizador e palavra passe que autorizam o acesso ao sítio de introdução de dados. Em 2011, quatro regiões francesas ainda não tinham médicos referenciadores e as regiões onde o dispositivo mais se desenvolveu são aquelas que possuem médicos referenciadores que fizeram parte da equipa que inicialmente apresentou o projeto a nível nacional. Cada região tem independência de funcionamento e de gestão e o médico referenciador deverá igualmente contribuir para constituir, manter e estruturar a rede da sua região, com o objetivo de assegurar o financiamento e a logística do projeto a este nível. Esta atividade do médico referenciador regional é mais ou menos facilitada em função do serviço em que ele trabalha, do caracter mais ou menos estruturado dos atores regionais da saúde no trabalho e do seu posicionamento mais ou menos favorável ao EVREST. A constituição da rede e a sua consolidação ao nível regional levam tempo e devem, frequentemente, ultrapassar múltiplos obstáculos, o que contribui para um desenvolvimento regional do EVREST bastante desigual. A rede, em certas regiões, abriu-se a uma colaboração com outros parceiros institucionais (observatórios regionais de saúde, direções regionais do trabalho, Instituto de medicina do trabalho, ...). Em função das particularidades das regiões que podem estar associadas à inserção profissional do médico referenciador, à história das regiões, mas também a personalidades do lado das "instituições" no campo da saúde no trabalho (académicos em saúde no trabalho, inspeções médicas, ...), as 
alianças encontradas em torno do EVREST e as redes de atores implicadas não são as mesmas. Os modos de integração do EVREST nas preocupações dos atores regionais da saúde no trabalho podem, pois, ser sensivelmente diferentes. Todas estas questões emergem no âmbito das reuniões dos médicos referenciadores regionais, que se encontram duas vezes por ano, com a equipa de projeto, com o objetivo de partilhar as suas experiências, dificuldades e os usos do EVREST.

O trabalho em rede é uma outra especificidade do EVREST e não apenas para os médicos referenciadores regionais. Em várias regiões, os referenciadores estatísticos EVREST foram sendo gradualmente auxiliados no tratamento dos dados regionais. Em associação com o médico referenciador eles também dão auxílio aos médicos do trabalho que optam por usos específicos do EVREST (em empresa). Estes referenciadores estatísticos demonstraram interesse em constituir ligações entre eles e encontram-se (pelo menos duas vezes por ano) para partilhar as suas experiências, identificar os recursos associados e desenvolver uma cultura comum sobre o EVREST e, mais geralmente, sobre as abordagens da saúde no trabalho.

Outras redes foram sendo criadas de forma mais pontual em torno do EVREST. Assim, os médicos interessados associaram-se para realizar um trabalho em comum sobre certas profissões como os ajudantes domiciliários ou os lixeiros. Numa região, alguns médicos reuniram-se com colegas para um intercâmbio em torno de apresentações de resultados provenientes de investigações específicas em empresas, e a forma de integrar os seus conhecimentos qualitativos. É possível que a introdução de questões "livres" suscite a necessidade de encontrar formas de intercâmbio e de coordenação entre os médicos que desejam aprofundar temáticas particulares. É ainda muito cedo para o dizer, mas parece bem que o uso do EVREST e o modo de estruturação do dispositivo favoreça até então, pelo menos para uma parte dos médicos participantes, modalidades de intercâmbio que se situam um pouco fora dos quadros habituais da profissão e que abordem tanto o seu uso do EVREST como a sua integração na sua prática profissional.

\section{Um dispositivo em tensão}

Como tentamos demonstrar, o dispositivo EVREST é, por construção, um dispositivo sempre em tensão. A sua validade só será reconhecida no campo científico se ele trouxer uma contribuição original e de qualidade na produção de conhecimentos em saúde no trabalho, mas a sua existência e a sua perenidade repousam sobre a participação de médicos de terreno de forma voluntária, que aí devem encontrar um interesse durável para a sua própria prática. Esta característica de objeto-fronteira é o que faz a sua originalidade e a sua riqueza, mas também o que o torna frágil.

\subsection{Uma amostra representativa?}

53 Uma primeira interrogação diz respeito à qualidade da amostra nacional, constituída unicamente com base no questionário dos trabalhadores nascidos em Outubro dos anos pares.

54 Ora, é importante relembrar que apenas médicos voluntários participam no EVREST. Não se trata apenas de uma escolha metodológica associada às dúvidas que poderíamos ter sobre a qualidade dos dados recolhidos e sobre a possibilidade de inscrever o 
dispositivo na durabilidade se um médico não estivesse interessado pelo EVREST. A abordagem de desenvolvimento do dispositivo, na medida em que visa uma participação ativa dos médicos, não foi de fazer para que o máximo de médicos se inscreva a todo o custo, mas de construir pouco a pouco redes com aqueles que o desejem, isto porque os médicos são atores do dispositivo, os que contribuem para a sua construção e para o manter vivo (nomeadamente nas regiões), mas também aqueles que podem "dar um sentido aos dados" através da sua experiência clínica. Estas escolhas envolvem, no entanto, dificuldades em particular para assegurar a representatividade da amostra : para se inscrever numa região, é necessário ter sido iniciada uma rede e um médico que deseje voluntariamente tornar-se referenciador; a participação dos médicos no seio de uma região pode variar segundo os serviços e a maior ou menor proximidade, intelectual ou geográfica, com o médico referenciador ; a participação dos médicos de serviços autónomos ou de funções públicas é menos importante que a dos médicos de serviços interempresas de saúde no trabalho ${ }^{15}$, etc. Estas dificuldades têm um impacto ainda mais forte na perspetiva de acompanhamento longitudinal (ao qual retornaremos).

Apesar destes limites, considerando o grande número de médicos que se inscreveram até então no dispositivo, a amostra nacional do EVREST é muito importante (ver tabela acima). Assim, para os anos 2008-2009, a exploração pode incidir sobre 22298 trabalhadores. As características desta amostra foram comparadas, sobre algumas variáveis socioprofissionais, com outras amostras nacionais e, globalmente, a amostra do EVREST parece bastante consistente com estas fontes. É preciso, no entanto, manterse prudente na leitura dos resultados descritivos, nomeadamente se se trata de apreciar os níveis (de uma ou outra característica profissional ou de saúde). A não representatividade da amostra é acentuada ao nível regional e a comparação dos resultados regionais entre eles é de difícil previsão visto que as diferenças de estruturas das populações dos trabalhadores inquiridos, resultam tanto da diversidade de estruturas socioeconómicas regionais como participações desiguais dos serviços no interior de cada região. A utilização do EVREST para comparar grupos profissionais (categorias socioprofissionais, sectores de atividade, etc.) parece, pelo contrário, um pouco menos sensível aos problemas de representatividade e o tamanho potencialmente relevante da base do EVREST torna-se uma das raras fontes que permite investigações sobre as relações entre o trabalho e a saúde num grande número de subpopulações alvo. Foram já iniciados trabalhos com esta perspetiva. ${ }^{16}$

Algumas informações sobre a medicina do trabalho em França

A organização da medicina do trabalho em França é regida pelo código do trabalho. Ela aplica-se a todos os trabalhadores assalariados. Os médicos do trabalho exercem a sua atividade quer em empresas de serviços autónomas no seio de grandes empresas ou em serviços interempresas. Os médicos do trabalho têm um papel exclusivamente preventivo em matéria de riscos profissionais, fora os primeiros socorros. As suas ações dividem-se entre ações de prevenção sobre o meio de trabalho e consultas médicas dos trabalhadores. É suposto eles informarem e aconselharem o empregador sobre os riscos associados à atividade de trabalho e sobre a saúde coletiva dos trabalhadores. Eles participam em debates sobre a saúde e segurança dos trabalhadores, nomeadamente nos comités de higiene, segurança e condições de trabalho.

Podem distinguir-se diversos tipos de consultas médicas nomeadamente : consultas de contratação, consultas ditas periódicas ou sistemáticas (programadas no máximo todos 
os dois anos) - para certas exposições ou situações de trabalho, uma vigilância médica reforçada está prevista nos textos e, em caso de problema de saúde, consultas médicas por pedido (do trabalhador, do empregador ou do médico) e consultas de retoma do trabalho (sempre que o trabalhador tenha estado de baixa, com uma duração definida por lei, variável de acordo com o contexto). Os textos preveem que as consultas médica deem lugar ao estabelecimento de um certificado médico de aptidão ao posto de trabalho.

Devido à pirâmide etária dos médicos do trabalho, o seu número está em forte diminuição há alguns anos (eles são cerca de $5700 \mathrm{em}$ atividade atualmente) e esta tendência deve acentuar-se nos próximos anos. Este défice de médicos levou a reflexões sobre uma reforma que está em curso e que prevê, nomeadamente, um grande número de enfermeiros de saúde no trabalho nas equipas pluridisciplinares coordenados pelos médicos do trabalho.

O segundo obstáculo é bastante dependente do contexto atual de escassez de médicos do trabalho e de incerteza sobre o quadro jurídico de funcionamento dos serviços de saúde no trabalho (ver quadro), refere-se ao facto de ter uma amostra que não sobre ou sob - represente os problemas de saúde. Esta questão está bastante ligada ao modo de organização das consultas e às ocasiões que os trabalhadores têm para se encontrarem com os médicos do trabalho. A priori, todos os trabalhadores assalariados seguidos pela medicina do trabalho são suscetíveis de entrar no EVREST, caso tenham um emprego com uma duração de pelo menos dois meses (onde estão também incluídos os trabalhadores temporários). E, para evitar a sobre representação daqueles que têm problemas de saúde ou trabalhadores que estão na empresa há muito pouco tempo, o questionário deveria ser passado no âmbito das consultas sistemáticas de saúde no trabalho (que cada trabalhador deve ter, qualquer que seja o seu estado de saúde e as suas exposições profissionais, seja anualmente ou de dois em dois anos) - ou até em consultas de contratação, se estas tiverem lugar pelo menos dois meses depois da contratação, ou ainda nas visitas de retoma após uma baixa de curta duração. Interrogar os trabalhadores durante a consulta sistemática pode, no entanto, introduzir alguns vieses em vários sentidos: inevitavelmente o de sobre representar os trabalhadores de boa saúde, visto que apenas aqueles que não estão de baixa de longa duração podem participar, mas também, como os médicos do trabalho têm cada vez menos tempo para consagrar às consultas sistemáticas, o de sobre representar os trabalhadores que têm condições de trabalho difíceis, se estes beneficiarem de uma "vigilância médica reforçada" e são, por isso, mais suscetíveis de terem consultas sistemáticas mais recorrentes. Para remediar em parte estas dificuldades, as explorações nacionais do EVREST baseiam-se sobre fichas de dois anos consecutivos (apenas a visita mais recente é utilizada para os trabalhadores que são vistos duas vezes no mesmo período). Contudo, em função das evoluções do quadro regulamentar dos serviços de saúde no trabalho (em plena reforma no momento em que este artigo foi escrito), é provável que cooperações para algumas funções no seio dos serviços (nomeadamente através de um aumento das responsabilidades do pessoal de enfermagem) podem conduzir à revisão dos modos de organização das consultas sistemáticas e, logo, das condições de utilização do questionário EVREST. Isto pode provavelmente proporcionar condições de melhoria da qualidade da amostra, mas também novas questões para o debate, caso exista uma participação mais ativa de outros atores que não o médico do trabalho na recolha de dados. 


\subsection{0 desafio do longitudinal}

61 permitir assegurar por um lado "fotografias" repetidas no tempo do trabalho e da saúde, mas também um acompanhamento do trabalho e da saúde dos trabalhadores assalariados. Os dados longitudinais são efetivamente necessários ao estudo das relações entre as condições de trabalho e da saúde, permitindo explorações diacrónicas (Molinié \& Pueyo, no prelo).

Tecnicamente, o acompanhamento longitudinal está assegurado no respeito do anonimato, graças a um algoritmo de Hash (ou de dispersão), que cria um identificador único por trabalhador a partir das informações de identificações estáveis no tempo. A utilização deste identificador permite um acompanhamento dos trabalhadores, independentemente do seu lugar de trabalho (empresa, região, ...). No entanto, este pressupõe uma re-interrogação regular pelos médicos do trabalho participantes. Só poderão, pois, ser acompanhados os trabalhadores que estejam empregados, cujo médico do trabalho participe no EVREST, que sejam vistos no âmbito de uma consulta periódica (ou semelhante) e que voltem. Ora, a instabilidade do emprego, o aumento da precaridade e do turn over diminuem a probabilidade que um trabalhador seja seguido de forma regular no âmbito das consultas sistemáticas. Para além disso, a evolução do contexto regulamentar e a demografia dos médicos do trabalho conduzem a um espaçamento das consultas. Até à data, a recolha é ainda insuficiente para nos permitir de quantificar a fração de trabalhadores que poderá ser acompanhada, mas sabemos já que a parte das consultas sistemáticas é cada vez mais reduzida na atividade de vários médicos do trabalho. Não é ainda possível fornecer os primeiros resultados longitudinais, visto que as análises só se baseiam sobre grupos de dois anos consecutivos e que o dispositivo só arrancou progressivamente a nível nacional, a partir de $2008^{17}$.

63 A reflexão sobre esta temática deverá ser continuada de forma a ancorar o dispositivo EVREST a longo-prazo, em associação com as evoluções regulamentares no campo da saúde no trabalho, dando sempre um papel essencial aos médicos do trabalho.

Mais, visto que a participação dos médicos do trabalho se baseia no voluntariado, é importante que o interesse deles pelo EVREST se mantenha ao longo do tempo, o que será ainda mais o caso se eles desenvolverem usos específicos do dispositivo, sozinhos ou em coordenação com colegas. Contudo, é também essencial para o dispositivo que eles compreendam o interesse (para além do compromisso formal que assumem no momento da sua inscrição) de contribuir para a construção da base nacional, que não é apenas para situar os seus dados num conjunto mais vasto (sectores, profissão,...) mas também para permitir trabalhos científicos que contribuam, a um outro nível, para as reflexões sobre a saúde no trabalho. Ora, é certo que tornar o EVREST durável apenas para os trabalhadores assalariados que constituem a amostra nacional - quase sempre em número insuficiente para permitir a produção de resultados locais pertinentes - é pouco motivador para que um médico continue a participar no dispositivo (apesar do seu compromisso inicial), por outro lado, o interesse suscitado pelo uso específico, pode conduzir ao "esquecimento" de interrogar os trabalhadores que fazem parte da amostra nacional, se eles não estão na empresa ou no sector alvo para estas investigações particulares. 
Por construção, a amostra e o seu acompanhamento longitudinal são tecnicamente problemáticos, visto que dependem estreitamente da taxa de cobertura do dispositivo, do compromisso durável dos médicos participantes, e da possibilidade, no interior da organização da medicina do trabalho, de assegurar um acompanhamento regular dos trabalhadores o mais independentemente possível das suas "exposições" ou do seu estado de saúde. Ainda sobre este ponto, é evidente que a possibilidade de sobrevivência do dispositivo e também do acompanhamento longitudinal, não pode ser pensada apenas de maneira "técnica". Ela está no centro da tensão, inerente ao dispositivo, entre usos a diferentes níveis e por diferentes profissionais. Avançar sobre este ponto implicará certamente a inscrição de todos os resultados nas características e limites do dispositivo, mas também de conceder uma grande atenção às atividades de articulação, de construção e de animação de diversas redes, para que as preocupações resultantes da atividade de cada um dos atores implicados e a diversidade dos pontos de vista se possam exprimir e ser postos em debate. É, sem dúvida, esta a condição para que o EVREST possa continuar a ser, por um lado, um dispositivo de produção de conhecimento a nível nacional, conhecimento enriquecido pela participação ativa dos que os produzem, e por outro, um dispositivo de uso local para contribuir à visibilidade das questões de trabalho e saúde nas empresas, tendo o apoio de uma rede de reflexão e das possibilidades de comparação que ultrapassam o contexto local.

\section{BIBLIOGRAFIA}

Archambault C., Doppler F., Tessoulin C., Stocker M.M., Beaugrand M., Jacquet C., Niezborala M., Tramier A., Sénécal S., Darbon L., Molinié A.-F. (2006). Observatoire Evrest, outil de veille et de suivi de la santé des salariés au travail dans le secteur aéronautique. Archives des maladies professionnelles et de l'environnement, vol. 67, $\mathrm{n}^{\circ} 2,333$.

Arnaudo B., Magaud-Camus I., Sandret N., Coutrot T., Floury M.-C., Guignon N., Hamon-Cholet S., Waltisperger D. (2004). L'exposition aux risques et aux pénibilités du travail de 1994 à 2003.

Premiers résultats de l'enquête SUMER 2003. Premières synthèses, DARES, décembre 2004, $\mathrm{n}^{\circ} 52.1$, 8 p. http://www.travail-emploi-sante.gouv.fr/IMG/pdf/

publication_pips_200412_n-52-1_exposition-risques-penibilites-travail.pdf

Askenazy P., Cartron D., de Coninck F., Gollac M. (coord.). (2006). Organisation et intensité du travail. Toulouse : Éditions Octarès.

Balogh I., Ørbæk P., Ohlsson K., Nordander C., Unge J., Winkel J., Hansson G.-A., the Malmö Shoulder/Neck Study Group. (2004). Self-assessed and directly measured occupational physical activities - influence of musculoskeletal complaints, age and gender. Applied Ergonomics, vol. 35, 49-56.

Bowker G., Star S.L. (1999). Sorting Things Out: Classification and its Consequences. Cambridge, MA : MIT Press. 
Bué J., Coutrot T., Hamon-Cholet S., Vinck L. (2007). Conditions de travail : une pause dans l'intensification du travail. Premières synthèses, DARES, janvier 2007, n 01.2, 7 p. http:// www.travail-solidarite.gouv.fr/IMG/pdf/2007.01-01.2.pdf

Célérier S. (2008a). Cancer et activités professionnelles des malades : les enseignements de trente ans de littérature internationale sur le thème. Sociologie et santé, n 28, juin, 185-199.

Célérier S. (2008b). Santé précaire au travail : quelques perspectives sociologiques. Connaissance de l'emploi, CEE, n 56, 1-4. http://www.cee-recherche.fr/fr/connaissance_emploi/56sante_precaire_travail_sociologie.pdf

Chassaing K., Waser A.-M. (2010). Travailler autrement. Comment le cancer initie un autre rapport au travail ? Travailler, $\mathrm{n}^{\circ} 23,99-126$.

Collège d'expertise sur le suivi statistique des risques psychosociaux au travail. (2009). Indicateurs provisoires de facteurs de risques psychosociaux au travail. Octobre 2009. http://www.collegerisquespsychosociaux-travail.fr/site/medias/Indicateurs-provisoires.pdf

Coutrot T., Molinié A.F. (2006). Des grandes enquêtes vers les indicateurs de santé en entreprise : les “ grandes enquêtes » et les médecins du travail. Archives des maladies professionnelles et de l'environnement, vol. 67, 2, 323-327.

Dejours C. (1993). Travail : usure mentale, de la psychopathologie à la psychodynamique du travail. Paris : Éditions Bayard.

Derriennic F., Touranchet A., Volkoff S. (1996). Estev, une méthode d'enquête. In F. Derriennic, A. Touranchet, S. Volkoff (coord). Âge, travail, santé. Études sur les salariés âgés de 37 à 52 ans. Enquête Estev 1990. Les Éditions Inserm, (collection Questions de santé publique). 33-54.

Desrosières A. (1993). La politique des grands nombres. Histoire de la raison statistique. Paris : La Découverte (Textes à l'appui).

Desrosières A. (2004). Enquêtes versus registres administratifs : réflexions sur la dualité des sources statistiques. Courrier des statistiques, $n^{\circ}$ 111, septembre 2004, 3-15. http://www.insee.fr/ $\mathrm{fr} / \mathrm{ffc} /$ docs_ffc/cs111b.pdf

Doppler F. (1995). Évolution de la population et transformation ou conception des situations de travail. In J.C. Marquié, D. Paumès et S. Volkoff (coord.). Le travail au fil de l'âge. Toulouse : Éditions Octarès. 411- 427.

Doppler F. (2004). Travail et santé. In Falzon P. (coord.). Ergonomie. Paris : PUF. 69-82.

Duquette J., Lortie M., Rossignol M. (1997). Perception of difficulties for the back related to assembly work : general findings and impact of back health. Applied Ergonomics, vol. 28, $\mathrm{n}^{\circ} \mathrm{s}$ 5-6, 389-396.

Falzon P., Doppler F. (1998). 10 ans après : l'évaluation à long terme d'une action ergonomique. XXXIIIe Congrès de la SELF. Paris, 16-17-18 septembre 1998. http://www.cnam.fr/ergonomie/ equipe/falzon/articles_pf/10\%20ans\%20apres_98.pdf

Fougeyrollas P. (2002). L'évolution conceptuelle internationale dans le champ du handicap : enjeux socio-politiques et contributions québécoises. Pistes, vol. 4, n² 2, novembre 2002. http:// www.pistes.uqam.ca/v4n2/articles/v4n2a12.htm

Gilles M. (2006). Genèse et usages d'un outil quantitatif en santé au travail dans une entreprise. Intérêts, limites et obstacles d'une démarche d'objectivation des liens entre santé et travail. Mémoire pour le master " Organisation, ressources humaines communication et emploi ». Spécialité Organisation 
de la production et de l'entreprise. Université de Marne la Vallée. En ligne sur le site Evrest : http://evrest.istnf.fr/_admin/Repertoire/fckeditor/file/Docs_PDF/MemoireMasterMGilles.pdf

Gilles M., Volkoff S. (2009). Quantifier la santé au travail en entreprise : acteurs, conventions, usages. Article de synthèse à la suite de la convention ANR n 05954/ANR 05 SEST 032-01. Disponible sur le site de l'ANR http://www.agence-nationale-recherche.fr/documents/uploaded/ 2009/SEST2005/28wolkoff.pdf

Gollac M. (1997). Des chiffres insensés ? Pourquoi et comment on donne un sens aux données statistiques. Revue française de sociologie, $\mathrm{n}^{\circ}$ XXXVIII-1, 1-36.

Gollac M., Volkoff S. (2007). Les conditions de travail. Paris, Éditions La Découverte (Collection Repères), $\mathrm{n}^{\circ} 301$.

Laville A. (1998). Les silences de l'ergonomie vis-à-vis de la santé. In Actes du colloque "Recherche et ergonomie » - Toulouse 1998. 151-158. http://www.ergonomie-self.org/media/media30419.pdf

Lhuilier D., Amado S., Brugeilles F., Diallo M., Rolland D. (2010). Le travail et l'emploi à l'épreuve du VIH/VHC ? : régulations des systèmes d'activités et réévaluation du modèle de vie. @ctivités, vol. 7 (2), 2-26. http://www.activites.org/v7n2/v7n2.pdf

Millanvoye M., Colombel J. (1996). Âge et activité des opérateurs dans une entreprise de construction aéronautique. In R. Patesson (dir.) Intervenir par l'ergonomie, XXXIe Congrès de la SELF, Bruxelles. vol. 2, 39-46.

Minaire P. (1992). Disease, Illness and Health : The critical Models of the Disablement Process, Bulletin of the World Health Organization, vol. 70 (3), 373-379.

Molinié A.-F., Volkoff S. (2000). Intensité du travail et santé dans un organisme administratif : une enquête à l'Agence nationale pour l'emploi. PISTES, vol. 2, n 1, mai 2000.

Molinié A.-F. (2003). Interroger les salariés sur leur passé professionnel : le sens des discordances. Revue d'épidémiologie et de santé publique, $\mathrm{n}^{\circ}$ 51, p. 589-605.

Molinié A.-F. (2006a). La santé au travail des salariés de plus de 50 ans. In Insee, Données sociales, La Société Française. Édition 2006. 543-553. http://www.insee.fr/fr/ffc/docs_ffc/donsoc06zi.pdf

Molinié A.-F. (2006b). Les salariés quinquagénaires, entre fragilisation et protection. Retraite et société, $\mathrm{n}^{\circ} 49,12-37$.

Molinié A.-F., Pueyo V. (à paraître). Les dynamiques temporelles des relations santé travail, et le fil de l'âge. In Molinié, Gaudart, Pueyo (coord.). La vie professionnelle : âge, expérience et santé à l'épreuve des conditions de travail. Toulouse : Éditions Octarès (Travail et activité humaine).

Molinié A.-F., Volkoff S. (1982). Quantifier les conditions de travail ? Travail et Emploi, $\mathrm{n}^{\circ} 11$, p. 63-70.

Nagi S.Z. (1964). A study in the evaluation of disability and rehabilitation. Potential concepts, methods, and procedures. American Journal of Public Health, vol. 54, n 9, 1568-1579.

Star S.L. (2010). Ceci n'est pas un objet-frontière ! Réflexions sur l'origine d'un concept. Revue d'anthropologie des connaissances, 2010/1, vol. 4, n 1, 18-35.

Star S.L., Griesemer J.R. (1989). Institutional Ecology, 'Translations' and Boundary Objects : Amateurs and Professionals in Berkeley's Museum of Vertebrate Zoology, 1907-1939. Social Studies of Science, vol. 19, $\mathrm{n}^{\circ} 3,387-420$.

Teiger C., Laville A. (1991). L'apprentissage de l'analyse ergonomique du travail, outil d'une formation pour l'action. Travail et Emploi, $\mathrm{n}^{\circ} 47,10 \mathrm{p}$. http://ecrire.travail-solidarite.gouv.fr/ publications/Revue_Travail-et-Emploi/pdf/47_3091.pdf 
Trompette P., Vinck D. (2009). Retour sur la notion d'objet-frontière. Revue d'anthropologie des connaissances, 2009/1, vol. 3, $\mathrm{n}^{\circ} 1,15-27$.

Trompette P., Vinck D. (2010). Retour sur la notion d'objet-frontière (2). Fécondité de la notion dans l'analyse écologique des objets innovants. Revue d'anthropologie des connaissances, 2010/1, vol. $4, \mathrm{n}^{\circ} 1,11-15$.

Volkoff S. (2008). L'intensité du travail “ disperse » les problèmes de santé. In de Terssac G., Saint-Martin C. et Thébault C. (coord.). La précarité : une relation entre travail, organisation et santé. Toulouse : Éditions Octarès. 29-40.

Volkoff S. (coord.) 2005. L'ergonomie et les chiffres de la santé au travail : ressources, tensions et pièges. Toulouse : Éditions Octarès.

Volkoff S., Molinié A.-F. (2010). Quantifier sans broyer ? Les statistiques en santé au travail à la rencontre des analyses cliniques. In D. Lhuilier et Y. Clot (coord.). Travail et santé- Ouvertures cliniques. Toulouse : Éditions Erès (Clinique du travail). 175-188.

Wood P.H.N. (1975). Classification of Impairments and Handicaps, World Health Organization, (WHO/ ICD 9/REV. CONF/75, 15).

World Health Organization (WHO) (1980). International Classification of Impairments, Disabilities, and Handicaps, Geneva : World Health Organization (Reprint 1993).

\section{ANEXOS}

Data __________ Nome do medico : SST :

introdução _-

EVREST 2011

Apelido : Nome : sexo : _- data de nascimento : trabalhador : PCS-ESSE :

Naturalidade : NAF2008 :

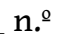

Empresa : trabalhadores :

Atelier (facultativo) : Campo livre (facultativo) :

Condições de trabalho

Mudou de trabalho no último ano ? Sim Não

Em caso afirmativo, foi por motivos médicos? Sim Não

Trabalha a tempo inteiro ? Sim Não

Habitualmente, tem um horário normal ? Sim Não

Tem regularmente :

Intervalos superiores a duas horas Sim Não 
Horários desfasados (muito cedo da parte da manhã e até muito tarde à noite) Sim

Não

Horários irregulares ou alternados Sim Não

Trabalho noturno (entre as oh e as $5 \mathrm{~h}$ ) Sim Não

Faz regularmente deslocações profissionais de mais de $24 \mathrm{~h}$ ? Sim Não

\section{Constrangimentos de tempo}

Em função da carga de trabalho, acontecem situações em que :

\begin{tabular}{|l|l|l|l|l|}
\hline & Nunca & Raramente & Frequentemente & $\begin{array}{l}\text { Muito } \\
\text { frequentemente }\end{array}$ \\
\hline $\begin{array}{l}\text { Ultrapassam os horários normais de } \\
\text { trabalho }\end{array}$ & & & & \\
\hline $\begin{array}{l}\text { Tem de eliminar ou encurtar uma } \\
\text { refeição, não fazer pausas }\end{array}$ & & & & \\
\hline $\begin{array}{l}\text { Tratar rapidamente de uma tarefa que } \\
\text { exige mais cuidados }\end{array}$ & & & & \\
\hline
\end{tabular}

Pode quantificar as dificuldades associadas à pressão temporal (necessidade de se apressar, fazer tudo muito rapidamente, ...)

Sem dificuldade 0 -10 Com elevada dificuldade

Tem necessidade de abandonar com frequência uma tarefa que estava a realizar para fazer uma outra que não estava prevista ?· Sim Não

Em caso afirmativo, diria que esta interrupção da atividade

- Perturba o seu trabalho Sim Não

- É um aspeto positivo do seu trabalho Sim Não

Avaliações sobre o trabalho : diria que o seu trabalho apresenta as seguintes características?

\begin{tabular}{|l|l|l|l|l|}
\hline & Nada & $\begin{array}{l}\text { Quase } \\
\text { nada }\end{array}$ & Parcialmente & Totalmente \\
\hline Permite aprender coisas & & & & \\
\hline Variado & & & & \\
\hline Pode escolher a forma de proceder & & & & \\
\hline $\begin{array}{l}\text { Tem possibilidades suficientes de entreajuda e } \\
\text { cooperação }\end{array}$ & & & & \\
\hline Tem meios para fazer um trabalho com qualidade & & & & \\
\hline
\end{tabular}




\begin{tabular}{|l|l|l|l|l|}
\hline $\begin{array}{l}\text { Tem o sentimento de que, no seu conjunto, o seu } \\
\text { trabalho é reconhecido pelos colegas }\end{array}$ & & & & \\
\hline Tem de fazer coisas que desaprova & & & & \\
\hline $\begin{array}{l}\text { Tem de trabalhar apesar do medo de perder o } \\
\text { emprego }\end{array}$ & & & & \\
\hline
\end{tabular}

Carga física do posto de trabalho : o seu posto de trabalho apresenta as características seguintes?

\begin{tabular}{|c|c|c|c|c|c|}
\hline & \multirow{2}{*}{$\begin{array}{l}\text { Não, } \\
\text { nunca }\end{array}$} & \multirow{2}{*}{$\begin{array}{l}\text { Sim, por } \\
\text { vezes }\end{array}$} & \multirow{2}{*}{$\begin{array}{l}\text { Sim, } \\
\text { frequentemente }\end{array}$} & \multicolumn{2}{|c|}{$\begin{array}{l}\text { Se sim, é difícil ou } \\
\text { penoso? }\end{array}$} \\
\hline & & & & Sim & Não \\
\hline Posturas obrigatórias & & & & & \\
\hline $\begin{array}{l}\text { Esforço, transporte de cargas } \\
\text { pesadas }\end{array}$ & & & & & \\
\hline Gestos repetitivos & & & & & \\
\hline $\begin{array}{lll}\text { Muitos e longos } & \text { e } & \\
\text { deslocamentos a pé } & \end{array}$ & & & & & \\
\hline $\begin{array}{l}\text { Manter-se de pé de forma } \\
\text { prolongada }\end{array}$ & & & & & \\
\hline
\end{tabular}

\section{Está exposto a :}

\begin{tabular}{|l|l|l|l|l|l|}
\hline & Sim & Não & & Sim & Não \\
\hline Produtos químicos & & & Condução prolongada & & \\
\hline Pó, fumos & & & Calor intenso & & \\
\hline Rx ionizante & & & Intempéries & & \\
\hline Vibrações & & & Pressão psicológica & & \\
\hline Desconforto sonoro & & Agentes biológicos & & \\
\hline Ruído > 80db & & $\begin{array}{l}\text { Contacto com o público (utilizadores, pacientes, } \\
\text { clientes, alunos, ...) }\end{array}$ & & \\
\hline $\begin{array}{l}\text { Constrangimentos } \\
\text { visuais }\end{array}$ & & & & \\
\hline
\end{tabular}

\section{Formação}


No último ano, esteve em formação ? Sim Não

Em caso afirmativo, era uma situação

Relacionada com o seu trabalho atual Sim Não

Relacionada com uma futura função Sim Não

De formação de interesse geral Sim Não

No último ano desempenhou o papel de formador, de tutor ? Sim Não

Estilo de vida

Realiza de forma regular (pelo menos 1 vez por semana) uma atividade desportiva?

Sim Não

Consumos habituais

Tabaco (número de cigarros por dia)

- Não fumador -----

- Antigo fumador -----

- Menos de 5 cigarros -----

- 5 a 15 cigarros -----

- > 15 cigarros -----

Café (número de chávenas por dia)

- Não bebe café -----

- 1 a 4 chávenas -----

- Mais de 4 chávenas -----

Tem deslocações casa/trabalho longas ou penosas ? Sim Não

Estado de saúde atual (a preencher pelo médico ou enfermeiro)

Última entrevista sistemática (ou de contratação) há : anos (0 se nunca fez entrevista ou se a última foi há menos de $1 \mathrm{ano}$ )

\begin{tabular}{|c|c|c|c|c|c|c|c|c|}
\hline \multirow{2}{*}{$\begin{array}{l}\text { Nada a } \\
\text { assinalar }\end{array}$} & \multirow{2}{*}{$\begin{array}{l}\text { Peso :__-__kg } \\
\text { Altura :_-_ cm }\end{array}$} & \multicolumn{2}{|c|}{$\begin{array}{l}\text { Queixas ou } \\
\text { sinais } \\
\text { clínicos }\end{array}$} & \multicolumn{2}{|c|}{$\begin{array}{l}\text { É um incómodo } \\
\text { no trabalho? }\end{array}$} & \multicolumn{2}{|c|}{$\begin{array}{l}\text { Tratamento ou } \\
\text { outro cuidado }\end{array}$} & \multirow[t]{2}{*}{$\begin{array}{l}\text { Coluna livre, } \\
\text { facultativa }\end{array}$} \\
\hline & & Sim & Não & Sim & Não & Sim & Não & \\
\hline & Cardio-respiratório & & & & & & & \\
\hline & $\begin{array}{l}\text { - Aparelho } \\
\text { respiratório }\end{array}$ & & & & & & & \\
\hline & $\begin{array}{l}\text { Aparelho } \\
\text { cardiovascular }\end{array}$ & & & & & & & \\
\hline
\end{tabular}




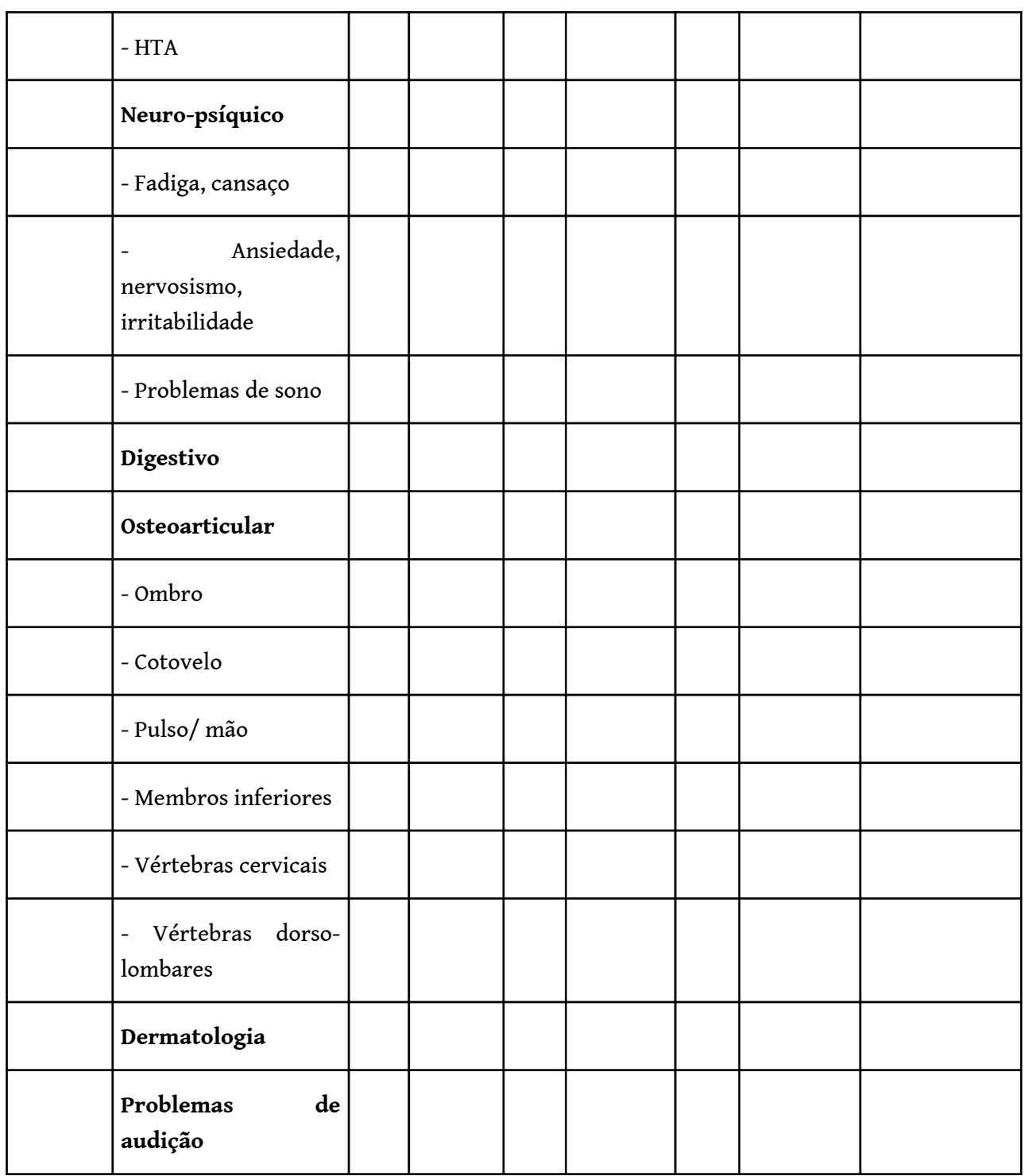

\section{NOTAS}

1. Evoluções e Relações em Saúde no Trabalho.

2. "Um objeto é qualquer coisa sobre e com a qual as pessoas (ou em informática, outros objetos e softwares) agem. A sua materialidade provém da ação e não de um sentido pré-fabricado da matéria ou da sua qualidade de coisa" (Star, 2010, p. 20).

3. Marion Gilles (Modys, Universidade de Lyon 2), tese de sociologia em curso sobre a direção de Michel Gollac. Tema da tese: Fabrications et usages sociaux des chiffres en santé-travail en entreprises. Enjeux et tensions autour de la représentation de la " santé au travail » (Construções e usos sociais dos números em saúde-trabalho nas empresas. Desafios e tensões em torno da representação da "saúde no trabalho").

4. Centro de Investigação e de Estudos sobre a Idade e as Populações no Trabalho.

5. Centre Interservices de Santé et de Médecine du travail en entreprise - Centro interserviços de saúde e de medicina do trabalho em empresa. Este organismo coordena os serviços interempresas de saúde no trabalho.

6. Um "colégio de peritagem" recebeu como missão formular proposições com vista a um acompanhamento estatístico dos riscos psicossociais no trabalho. Num primeiro relatório 
entregue em outubro de 2009 no Ministério do trabalho, propunham cerca de quarenta indicadores imediatamente disponíveis nas fontes estatísticas francesas existentes. Estes indicadores refletem seis dimensões selecionadas para analisar estes riscos: 1) exigências do trabalho, 2) exigências emocionais, 3) autonomia e margens de manobra, 4) a qualidade das relações no trabalho, 5) os conflitos de valor (problemas de ética e de consciência profissional), 6) insegurança do emprego e da carreira. Ver http://www.college-risquespsychosociaux-travail.fr 7. Ver nomeadamente investigações sobre o trabalho com cancro ou VIH/SIDA (Chassaing \& Waser, 2010 ; Lhuilier et al., 2010, Célérier, 2008a e b).

8. Não limitar ao domínio médico.

9. Saúde, trabalho e envelhecimento..

10. Alguns exemplos podem ser encontrados na Lettre Evrest que está disponível em http:// evrest.istnf.fr

11. A base de dados é alimentada por todas as fichas introduzidas no sítio pelos médicos participantes. Ela está alojada num servidor protegido e que foi objeto de uma autorização de implementação pela Commission nationale informatique et libertés (CNIL - Comissão nacional informática e liberdades). Os direitos de acesso estão também sujeitos a uma Carta de utilização que todos os participantes do dispositivo se comprometem a respeitar.

12. Agrupamento de interesse científico.

13. Os parceiros do GIS EVREST são: a Agence Nationale pour l'Amélioration des Conditions de Travail (ANACT - Agência Nacional para a Melhoria das Condições de Trabalho), Agence Nationale de Sécurité Sanitaire de l'Alimentation, de l'Environnement et du Travail (ANSES Agência Nacional de Segurança Sanitária da Alimentação, do Ambiente e do Trabalho), Centre de Recherches et d'Études sur l'Âge et les Populations au Travail (CREAPT- Centro de Investigações e Estudos sobre a Idade e as Populações no Trabalho), Institut de Santé au Travail du Nord de la France (ISTNF - Instituto de Saúde no Trabalho do Norte de França), Université Lille 2, Droit et Santé (Universidade Lille 2 - Direito e Saúde), Centre Interservices de Santé et de Médecine du Travail en Entreprises (CISME - Centro Interserviços de Saúde e de Medicina do Trabalho em Empresas), European Aeronautic Defence and Space Company (EADS - Empresa Europeia de Defesa Aeronáutica e Espaço).Um objeto é qualquer coisa sobre e com a qual as pessoas (ou em informática, outros objetos e softwares) agem. A sua materialidade provém da ação e não de um sentido pré-fabricado da matéria ou da sua qualidade de coisa" (Star, 2010, p. 20).

14. Presidente do conselho científico do GIS EVREST : Michel Gollac, diretor do laboratório de sociologia quantitativa CREST-INSEE. Os outros membros do conselho científico são: Ellen Imbernon, diretora do departamento de saúde no trabalho do instituto de vigilância na saúde ; Philippe Mairiaux, professor na Universidade de Liège (Bélgica), departamento de ciências e de saúde pública; Christophe Paris, professor de medicina do trabalho, Nancy; Valérie Pueyo, "maître de conférences" (professor auxiliar) de ergonomia na Universidade Lyon 2; Hélène Sultan-Taïeb, "maître de conférences" de economia na Universidade da Borgonha, Dijon.

15. Contudo, algumas grandes empresas usam já ou colocam em prática uma recolha de dados muito próxima do dispositivo nacional EVREST, mas independente no seu funcionamento. Existem intercâmbios entre os médicos que participam nestes diversos dispositivos, nomeadamente com o objetivo de estudar as possibilidades de aproximação.

16. Assim, a partir da amostra 2008-2009, resultados comparativos puderam ser apresentados em "Caractéristiques du travail, pression temporelle et gênes dans le travail liées à des lombalgies" (características do trabalho, pressão temporal e incómodos associados às lombalgias) para duas populações de trabalhadores masculinos : os trabalhadores de "tipo industrial" que trabalham no sector da indústria $(\mathrm{n}=1722)$ e os trabalhadores da construção $(\mathrm{n}=1505)$, (comunicação de A. Leroyer e A.F. Molinié no Congresso da Aderest em setembro de 2010, artigo em preparação). De outro modo, os primeiros números de EVREST Résultats apresentam os resultados, por um lado, sobre as características do trabalho e da saúde dos trabalhadores da grande distribuição (número 
1, março de 2011) e, por outro, sobre os trabalhadores das diversas profissões da construção (número 2, maio de 2011). Está em preparação um número sobre os "motoristas", em função do seu sector de atividade (dentro ou fora do sector dos transportes). Estes documentos podem ser obtidos no sítio http://evrest.istnf.fr

17. Uma primeira exploração das possibilidades de análise está, no entanto, em curso a partir de uma amostra dita equilibrada constituída por trabalhadores interrogados pelo menos uma vez durante os anos 2007 e 2008 e também pelo menos uma vez nos anos 2009 e 2010.

\section{RESUMOS}

O dispositivo EVREST (ÉVolutions et RElations en Santé au Travail) é um observatório plurianual por questionário, construído em colaboração com médicos do trabalho e investigadores, de forma a poder analisar e acompanhar diferentes aspetos do trabalho e da saúde dos trabalhadores assalariados. O seu objetivo é constituir uma base de dados nacional, a partir de uma amostra de trabalhadores assalariados, para realizar trabalhos de cariz científico e também permitir a cada médico (ou a equipas de médicos que se coordenam entre si) utilizar o Evrest para além da amostra nacional, em função das suas próprias preocupações. A sua construção faz parte de um processo que visa conciliar as exigências características de cada um desses "mundos" profissionais. Ela envolve a criação e a partilha de "objetos", partilha na qual cada um "encontra o que procura", mas também a elaboração progressiva de novas formas de coordenação e intercâmbio.

El dispositivo Evrest (EVoluciones y RElaciones en Salud en el Trabajo) es un sistema de monitoreo, que año tras año recolecta datos, mediante un cuestionario elaborado con la colaboración de médicos laborales e investigadores, para poder analizar y seguir diferentes aspectos del trabajo y de la salud de los asalariados. Su objetivo es constituir una base de datos nacional, sobre una muestra de asalariados, para realizar trabajos de carácter científico; pero también para permitir que cada médico (o grupo de médicos que coordinarían su trabajo) haga uso de Evrest mas allá de la muestra nacional en función de sus propias preocupaciones. Su construcción se inscribe dentro de un proceso dirigido a hacer compatibles las exigencias propias de cada uno de estos dos "mundos" profesionales. Implicó el crear y compartir "objetos", de una forma que fuera satisfactoria para todos los involucrados. También significó la elaboración progresiva de nuevas formas de coordinación y de intercambios.

Le dispositif EVREST (ÉVolutions et RElations en Santé au Travail) est un observatoire pluriannuel par questionnaire, construit en collaboration par des médecins du travail et des chercheurs, pour pouvoir analyser et suivre différents aspects du travail et de la santé de salariés. Il vise à constituer une base nationale, sur un échantillon de salariés, pour des travaux à caractère scientifique, mais aussi à permettre à chaque médecin (ou à des médecins qui se coordonneraient) d'utiliser Evrest au-delà de l'échantillon national en fonction de ses préoccupations. Sa construction s'inscrit dans un processus visant à rendre compatibles des exigences propres à chacun de ces “mondes" professionnels. Elle passe par la création et le partage d" objets", partage dans lequel chacun "retrouve son compte», mais aussi par l'élaboration progressive de formes nouvelles de coordination et d'échanges. 
EVREST (ÉVolutions et RElations en Santé au Travail) is a monitoring system, with data collected year after year by a questionnaire that was developed by a team of occupational physicians and researchers working together, in order to monitor and analyze various aspects of work and employee health. A national database on a sample of employees is thus being created that can be used for scientific work, but it also allows each doctor (or team of doctors who wish to coordinate their work) to make use of Evrest beyond the national sample in relation to their own concerns. Its development is part of a process aiming to reconcile the diverse and specific requirements of both professional worlds. It involved designing and sharing “ objects » in a way that would satisfy all the stakeholders. It also meant the gradual development of innovative ways for networking and exchanges.

\section{ÍNDICE}

Palabras claves: salud laboral, condiciones de trabajo, seguimiento longitudinal, médicos laborales, pluridisciplinariedad, objeto fronterizo

Keywords: occupational health, working conditions, longitudinal design, occupational health doctors, multidisciplinarity, boundary object

Mots-clés: santé au travail, conditions de travail, suivi longitudinal, médecins du travail, pluridisciplinarité, objet frontière

Palavras-chave: saúde no trabalho, condições de trabalho, monotorização longitudinal, médicos do trabalho, pluridisciplinaridade, objeto fronteira

\section{AUTORES}

\section{ANNE-FRANÇOISE MOLINIÉ}

CREAPT-CEE, 29, Promenade Michel-Simon, 93166 Noisy le Grand Cedex, France anne.molinie@cee-recherche.fr

\section{ARIANE LEROYER}

UDSL, Département Universitaire de Santé au Travail, Faculté de Medicine, 59045 Lille Cedex

France, ariane.leroyer@univ-lille2.fr 